\author{
Marcin KASPRZAK ${ }^{1^{*}}$ \\ Michal PYZALSKI ${ }^{1}$
}

\title{
TESTING OF FORCE SENSORS FOR THE ACTIVE MEASUREMENT AND LIMITATION OF AXIAL LOADS IN HEAVY TURNING
}

\begin{abstract}
This article describes the design and construction of a feed drive load measuring system based on industrial strain gauges installed in the machine tool structure. The system was calibrated and dynamically tested in the range of $15 \mathrm{kN}$ in real machining conditions. The tests showed that the system installed on a machine tool works correctly and its error amounts to about $5 \%$ of the measured range. Thanks to this measuring system the accuracy of the machine tool in machining conditions can be increased through the active compensation of the axial error caused by displacements. Moreover, the system can prevent tool breakage and increase machining efficiency.
\end{abstract}

\section{INTODUCTION}

As many of the production cost components are reduced today through diagnostics and active process supervision, these measures continue to be intensively investigated. One of the investigated problems is the diagnosis of the tool and machining process state. Such a diagnosis can be effected through the close monitoring of the vibrations or the forces occurring on the machine tool's controlled axes. In order to implement such a monitoring system it is necessary to test the sensors and to study the behaviour of this system integrated with a machine tool in cutting force load conditions.

In the case of heavy duty lathes, such as the lathes used to machine and renovate railvehicle wheelsets, it is necessary to control the machining process to ensure high productivity and automation. Also high machining process autonomy is desirable. It is essential to achieve vibration-free operation, high turned profile accuracy and a long cutting insert life under high cutting forces and in finishing operations. Therefore it is recommended to control both the cutting force and the machine tool's deformations manifesting themselves in displacements along the controlled axes. For this purpose it is necessary to integrate suitably matched force sensors, satisfying the machining process dynamics and dimensional stability criteria, with the machine tool. Recently, the investigation of machine tools and the machining process, aimed at meeting the above criteria has been the subject of numerous studies.

\footnotetext{
1 Department of Machine Tools and Mechanical Technologies, Wroclaw University of Science and Technology, Wroclaw, Poland

${ }^{*}$ E-mail email: michal.pyzalski@pwr.edu.pl https://doi.org/10.36897/jme/144597
} 
The monitoring of the operation of machine tool subassemblies is the subject of the paper [1] by Roy R. et al., where it is proposed to use intelligent sensors to dynamically monitor the wear of the individual machine tool subassemblies and the positioning accuracy and to correct errors by the machine itself. Monitoring problems are also discussed in the paper [2] by Verl A. and Frey. S., in which the effect of the feed rate on the change in ball screw nut preload is studied. Similar problems are considered by Jędrzejewski et al. in paper [3], in which the effect of a moving heat source (a ball screw nut) on the accuracy of positioning the lathe carriage toolhead is examined. Also noteworthy is Huang S.N. et al.'s paper [4] in which a system for monitoring the wear of the CNC machine's cutting tool through the monitoring of the cutting forces is defined. Similar investigations, taking into account the increase in the cutting force with cutting tool wear, were carried out by Jemielniak K. [5]. Stryczek R. in paper [6] presented an algorithm for the adaptive control of lathe feed, which significantly shortens machining time on the basis of the current loading of the machine's drives. The implementation and integration of measuring devices into spindle assemblies is extensively described by Abele E. et. al. in the paper [7]. Among papers on machine tool errors the ones devoted to thermal error diagnostics figure prominently. One of such papers [8] is by Brecher C. et al.

The first stage in the creation a monitoring system by the present authors is described in paper [9]. The system was created to improve the accuracy and productivity of a lathe used for machining rail-vehicle wheelsets. The machine's design is complicated and the forces exerted by its subassemblies reach high values. The forces are a source of much information about the cutting process conducted on this machine, whereby one can detect many of the arising anomalies and automate the machining process to a higher degree. The system being developed can improve the precision of the process thanks to an error compensation function based on the measurement of the forces. For the implementation of the system it is necessary to carry out detailed studies to determine the proper location of the sensors and to check if the measuring system transmits the forces correctly. An interesting idea on chip breaking was described by A. Astarloa et al in the paper [10].

\section{SELECTION OF SENSORS AND THEIR LOCATION IN MACHINE}

The aim of developing a system measuring the force loading the machine tool and the cutting tool during machining was to improve the precision and productivity a lathe used for reprofiling the wheelsets of rail vehicles. The system is based on the measurement of the forces occurring along the controlled axes during machining process execution. The measured force values provided a basis for creating a function for compensating machining errors along the controlled axes.

Suitable sensors had to be selected for the measuring system. The main precondition for selecting sensors was the possibility of permanently integrating the whole measuring system with the machine. Therefore the quality of workmanship of the sensors, the way of mounting them on the machine tool and their replaceability in case of a failure were important factors. A sensor suitable for this application should be characterized by a wide measuring range and should not occupy much space. Also the price was a significant limitation. Considering all 
the requirements, ring force sensors CL20-8 (Fig. 1) manufactured by ZEPWN were selected for the measuring system.

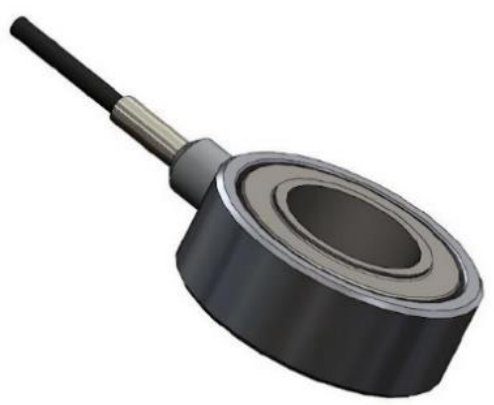

Fig. 1. Sensor CL20-8 used in designed measuring system

The sensors were installed in the ball screw area on the right and left carriage, whereby measurements along the two controlled axes became possible. Along axis $Z$ four strain gauge sensors CL20-8 were installed between the housing to which the ball screw nut was attached and the structural member of the machine's tool carriage. Along axis $X$ (the lathe's radial direction) three strain gauge sensors CL20-8 were installed between the rear ball screw bearing housing and the structural member to which this housing is attached. Axis $X$ and $Z$ are shown on Fig. 2.

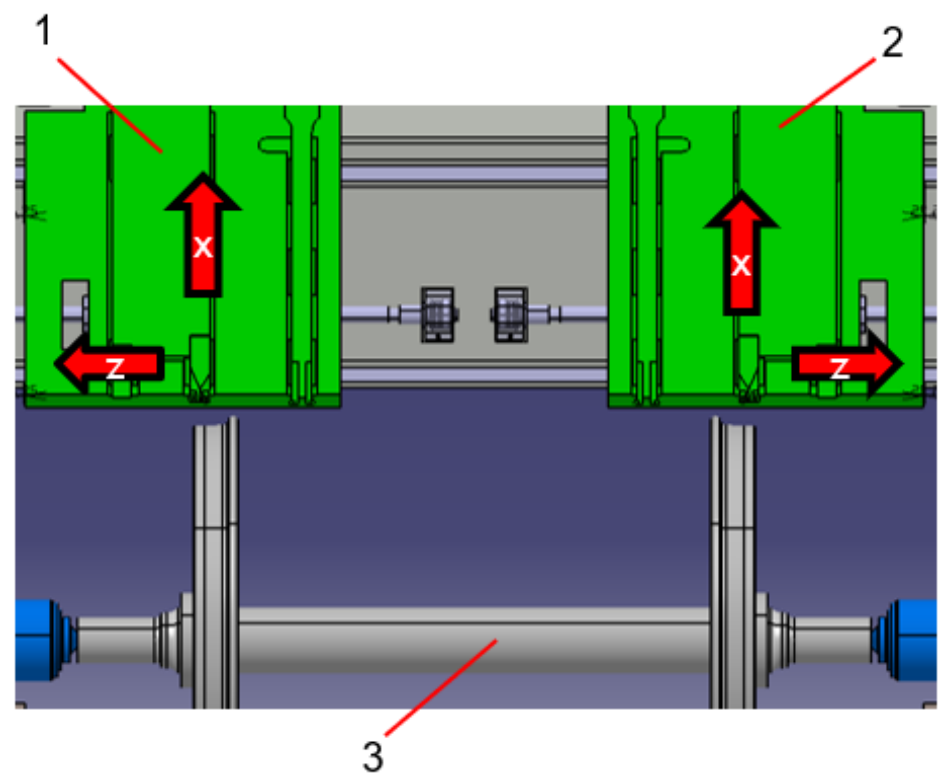

Fig. 2. Axis $\mathrm{X}$ and $\mathrm{Z}$ on the lathe.

These locations of the measuring system sensors were selected to maximally protect the latter against damage caused by the machining process and to most faithfully reflect the forces occurring on the controlled axes. Sensors of this kind are so designed that they are resistant to instantaneous overloads (even several times higher than the rated overload) which often occur during the operation of the lathe used for the machining of wheelsets. 


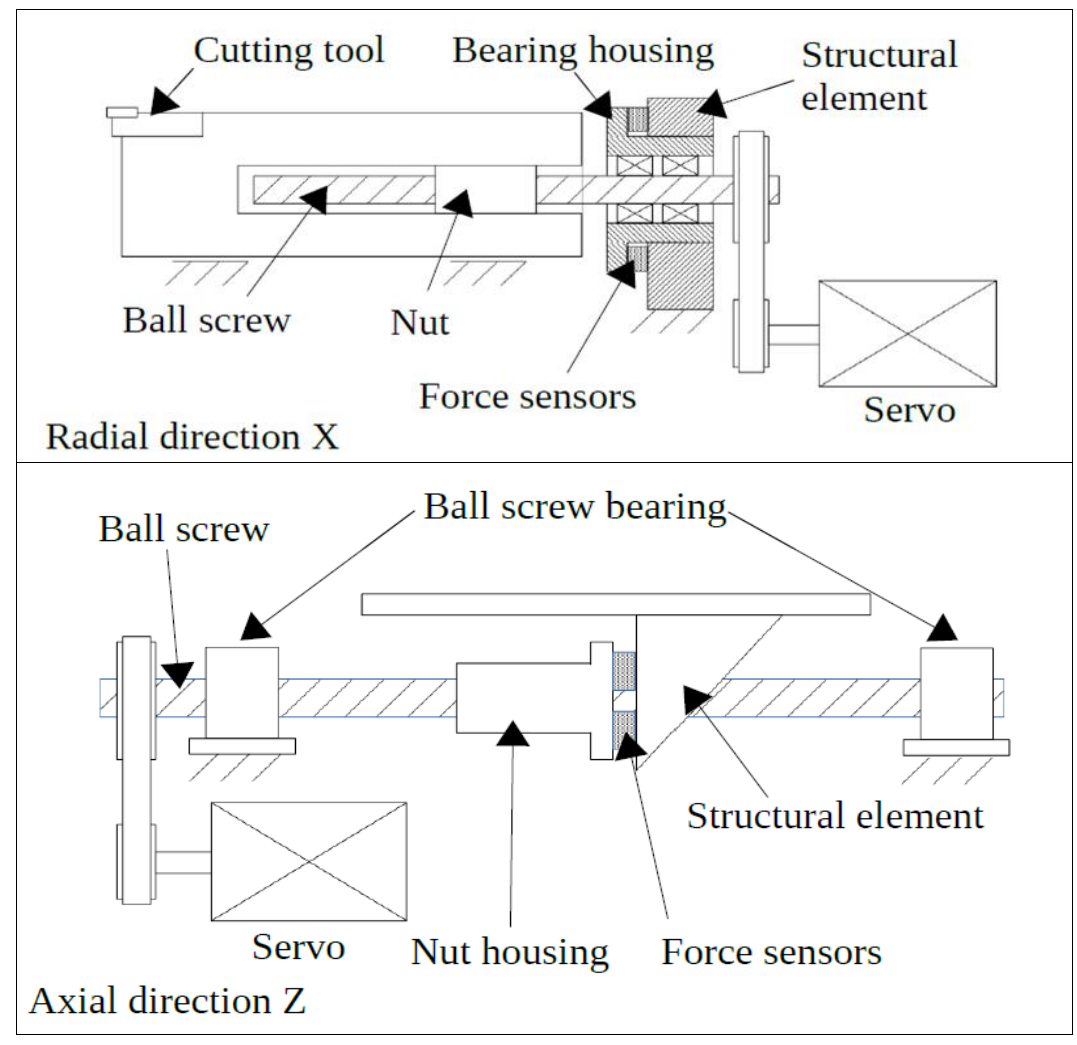

Fig. 3. Location of sensor on the lathe

\section{TESTING OF DESIGNED FORCE TRANSMISSION SYSTEM IN LABORATORY CONDITIONS}

The designed systems of transmitting forces in respectively the axial direction and in the radial direction were tested in a testing machine Zwick/Roell 1478. The two systems were subjected to forces acting axially and also to forces deviating from the axis by $4^{\circ}$ in different directions.

The exciting forces ranged from $-30 \mathrm{kN}$ to $30 \mathrm{kN}$ (the tensile force and the compressive force, respectively) for the system of force transmission in the axial direction and from $0 \mathrm{kN}$ to 30 $\mathrm{kN}$ (the compressive force) for the system of force transmission in the radial direction. The tests were described in detail in the earlier publication [9].

The mean relative errors due to differences between the sensor indications and the measuring machine readings amounted to:

- about $1.3 \%$ for the radial forces,

- about $5.5 \%$ for the forces deviating from the axis by $4^{\circ}$.

\section{CALIBRATION OF SENSORS ON MACHINE TOOL}

On the machine tool the sensors were calibrated by means of sensor FT5104125 made by Spais and hydraulic actuator TPH CLH10SA10 (Fig. 4). 
a)

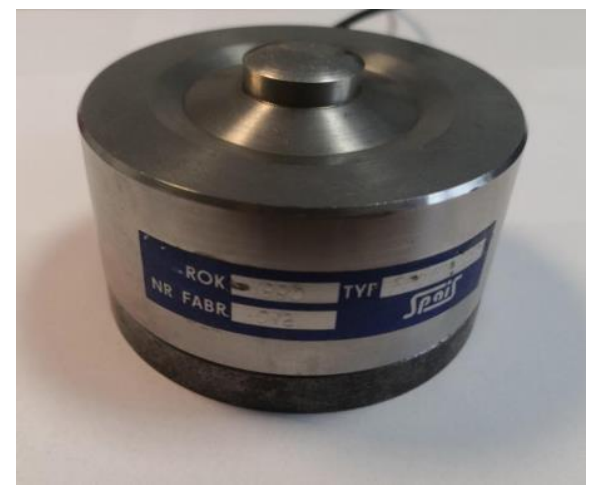

b)

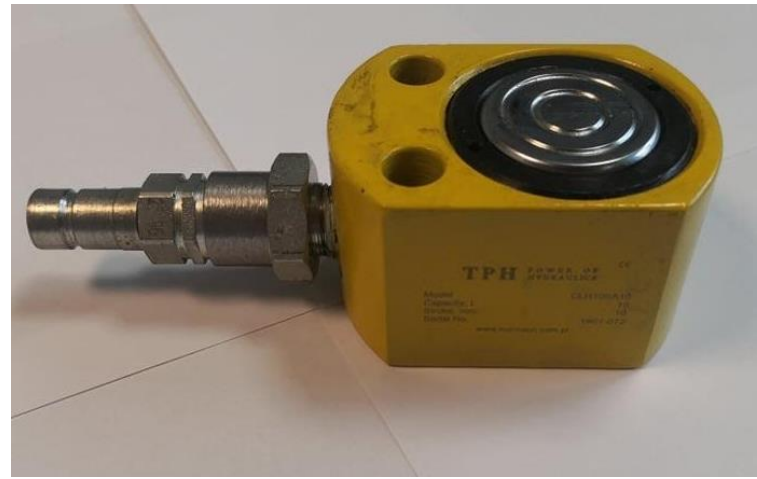

Fig. 4. Spais sensor FT5104125 (a) and hydraulic actuator TPH CLH10SA10 (b)

Prior to the calibration of the system the Spais sensor had been calibrated in the testing machine in the force range of $0-10 \mathrm{kN}$ in which the sensor's mean relative error amounts to $0.06 \%$ (Fig. 5).

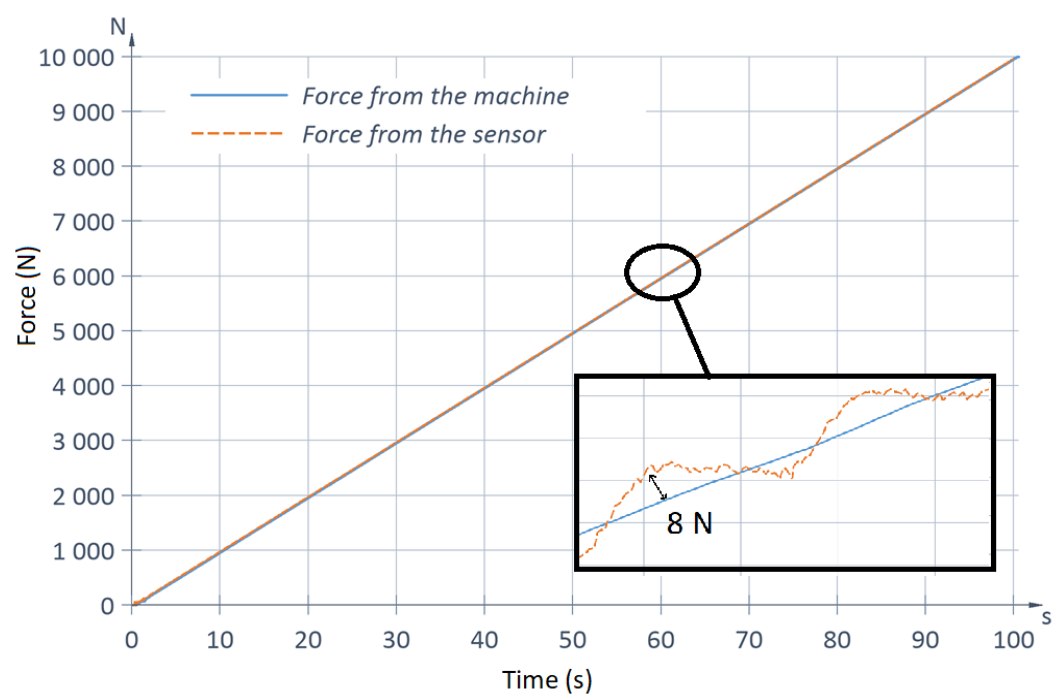

Fig. 5. Diagram showing force values indicated by testing machine and standard sensor during calibration

Then we set about calibrating the sensors installed on the lathe. For this purpose the standard sensor was attached to the hydraulic actuator which was secured to the lathe's tool carriage by means of a special holder. The force generated by the hydraulic actuator would be applied between the tool carriage and the wheelset. In the course of the test the force would increase and decrease stepwise from $0 \mathrm{kN}$ to $11.5 \mathrm{kN}$ (Fig. 6). Tests were carried out for the left carriage and the right carriage and axial direction $Z$ and radial direction $X$. A preliminary analysis of the graphs showed that the indications of the installed sensors diverged from the standard ones.

The above diagram (Fig. 6) shows that as the force exerted by the actuator increases, so does the difference between the values indicated by the sensors installed on axes $X$ and $Y$. In order to correct these differences appropriate correction factors were calculated. Their values are presented in the table below (Table 1). 


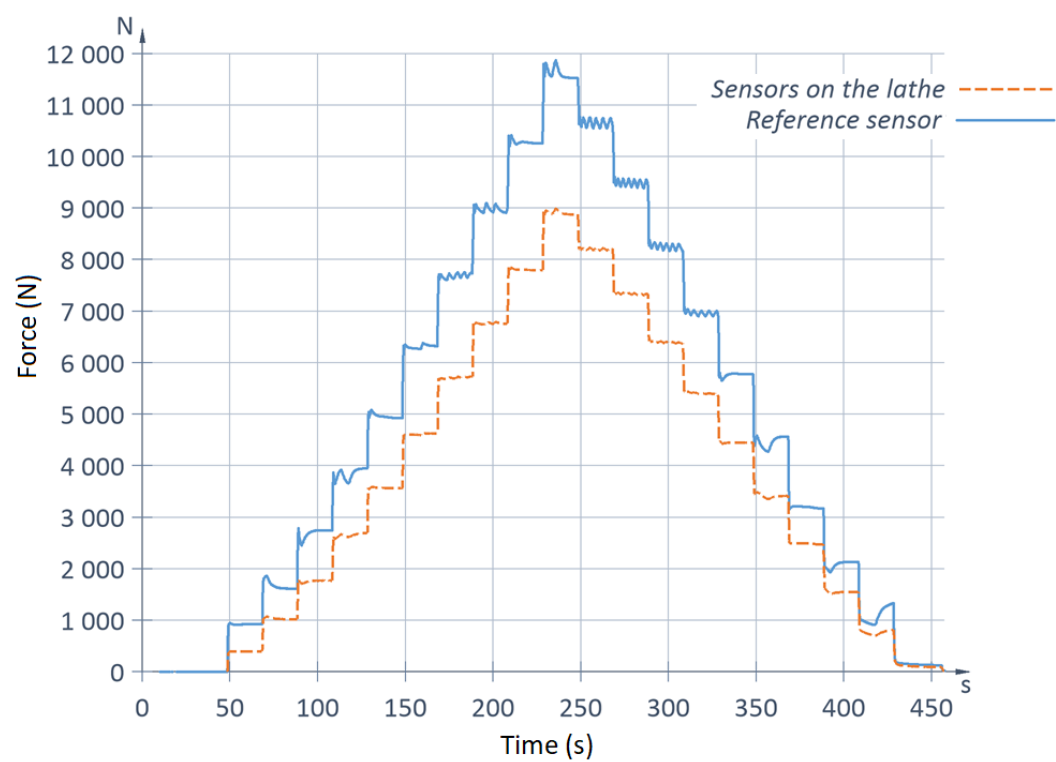

Fig. 6. Force values indicated by standard sensor and installed-on-lathe sensors during test

Table 1. Correction factors for both carriages

\begin{tabular}{|c|c|}
\cline { 2 - 2 } \multicolumn{1}{c|}{} & Correction factors \\
\hline Factor for sensors on left carriage axis X & 1.309599504 \\
\hline Factor for sensors on right carriage axis X & 1.352646247 \\
\hline Factor for sensors on left carriage axis Z & 1.359585812 \\
\hline Factor for sensors on right carriage axis & 1.216582705 \\
\hline
\end{tabular}

The diagram in Fig. 6 shows the standard sensor's signal values and the lathe sensors' signal values corrected using the previously calculated factors. The mean error of the sensor indications amounted to $4.95 \%$ (Table 2). Considering the wide range of measured forces, the calculated error value was a satisfactory result, whereby the sensors installed on the lathe could be used in further tests.

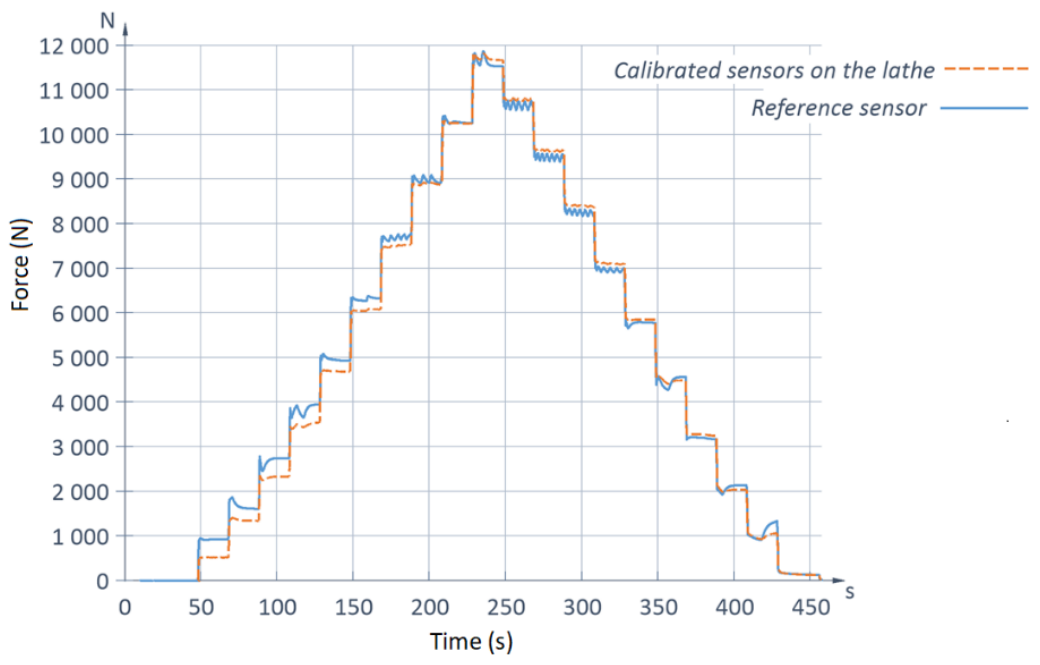

Fig. 7. Diagram showing force values indicated by standard sensor and calibrated values indicated by installed-on-lathe sensors during test 
It appears from the above diagram (Fig. 7) that in comparison with the standard sensor values the force values indicated by the calibrated sensors on the lathe carriage's axis $\mathrm{X}$ (the orange graph) show a larger divergence when the force increases than when the force decreases. This error could be due to backlashes on the tested axis. The force graphs obtained while testing the system along axis $\mathrm{Z}$ were equally satisfactory.

An increase in error with increasing test forces was observed, but the error did not exceed $5 \%$ of the range of the forces for which the system had been designed [9]. This result is satisfactory for both force growth and decline.

The largest mean error, amounting to $4.95 \%$ (Table 2), was noted for the sensors installed on axis $X$ on the machine's right side.

Table 2. Mean and maximum errors of sensors installed on lathe relative to standard sensor

\begin{tabular}{|l|c|c|c|}
\hline \multicolumn{1}{|c|}{ Sensors on axis } & $\begin{array}{c}\text { Maximum absolute error } \\
\max _{i \in\{1, \ldots, N\}}\left|x_{i}-t_{i}\right|\end{array}$ & $\begin{array}{c}\text { Mean absolute error } \\
\max _{i \in\{1, \ldots, N\}}\left|x_{i}-t_{i}\right|\end{array}$ & $\begin{array}{c}\text { Mean relative error } \\
N\end{array}$ \\
\hline Left side axis X & $707 \mathrm{~N}$ & $158 \mathrm{~N}$ & $2.98 \%$ \\
\hline Left side axis Z & $597 \mathrm{~N}$ & $172 \mathrm{~N}$ & $3.57 \%$ \\
\hline Right side axis X & $517 \mathrm{~N}$ & $329 \mathrm{~N}$ & $4.95 \%$ \\
\hline Right side axis Z & $401 \mathrm{~N}$ & $71 \mathrm{~N}$ & $1.45 \%$ \\
\hline
\end{tabular}

$t_{i}$ - the reference value for the $i$-th force measurement (the standard sensor),

$x_{i}$ - the force value for the $i$-th measurement by means of the tested measuring system,

$N$ - the number of measurements performed during the experiment.

\section{TESTING OF SYSTEM INSTALLED ON MACHINE TOOL}

The first test was carried out using the hydraulic actuator and the Spais force sensor. The actuator would generate sinusoidal forces characterized by different frequencies and amplitudes. The force excitation direction deviated by $45^{\circ}$ from the directions of axis $X$ and axis $Z$. In this configuration the standard sensor indicated the resultant value of the forces indicated by the sensors installed on axes $X$ and $Z$. This test additionally verified the system's performance in the transmission of the forces acting simultaneously in both the directions, i.e. in conditions close to the ones prevailing during machining. Figure 8 shows the course of the sinusoidal excitation test and the response of the force measuring system installed on the lathe.

The exciting force ranged from $0.5 \mathrm{kN}$ to $12 \mathrm{kN}$ while the frequency ranged from 0.02 $\mathrm{Hz}$ (Fig. 9) to $4 \mathrm{~Hz}$ (Fig. 10).

The sinusoidal excitation tests showed that the force measuring system installed on the lathe worked correctly at higher excitation dynamics and at synchronous operation of the two axes. For the frequency of $4 \mathrm{~Hz}$ a deviation is observed when the direction of loading changes. The deviation is due the system's inertia. Despite this, the system error did not exceed $5 \%$.

Then the system of sensors was tested with regard to the machining process. The wheelset was machined at the depth of cut of $4 \mathrm{~mm}, 8 \mathrm{~mm}$ and $10 \mathrm{~mm}$ and the feed rate of $2 \mathrm{~mm} / \mathrm{rev}$. The rate of feed was smoothly changed during the machining process by 
the operator. In the course of machining the forces were read at the signal sampling frequency of $2 \mathrm{kHz}$.

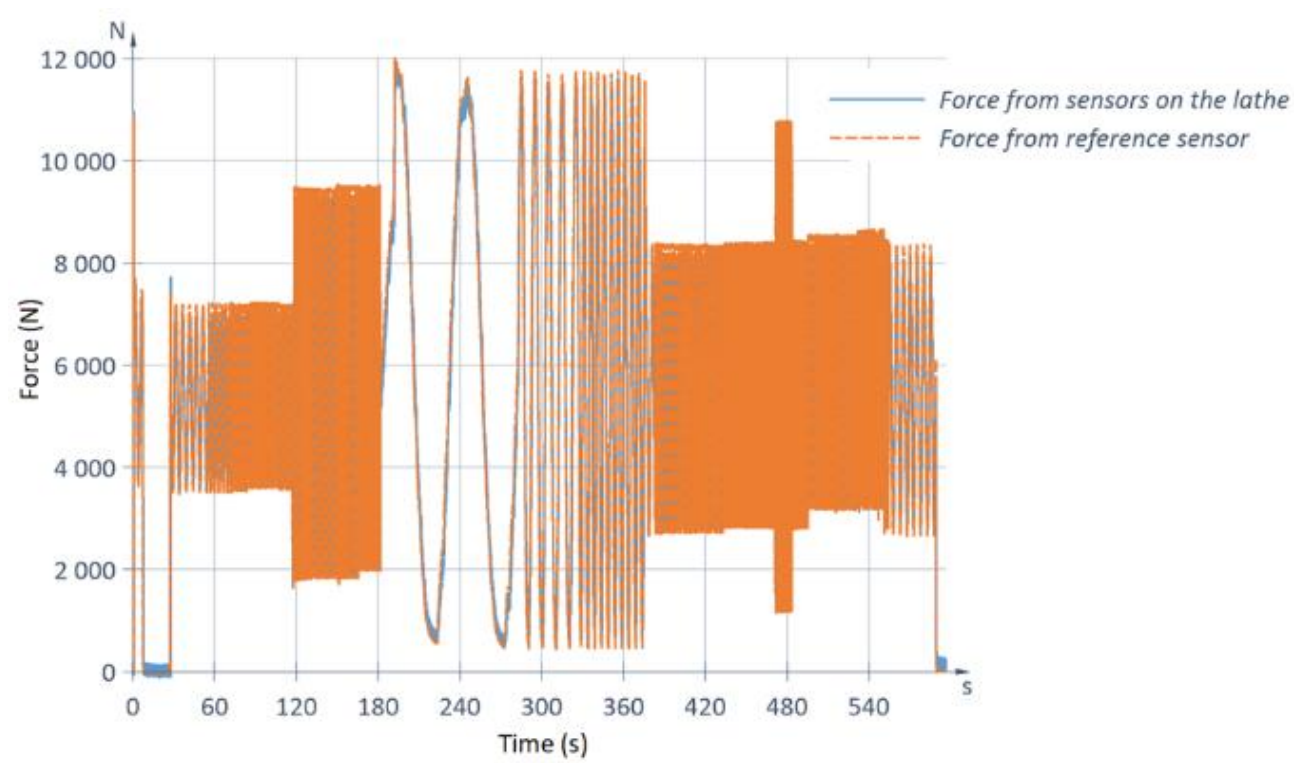

Fig. 8. Forces indicated by standard sensor and resultant force value obtained from sensors installed on lath on axes $X$ and $Z$

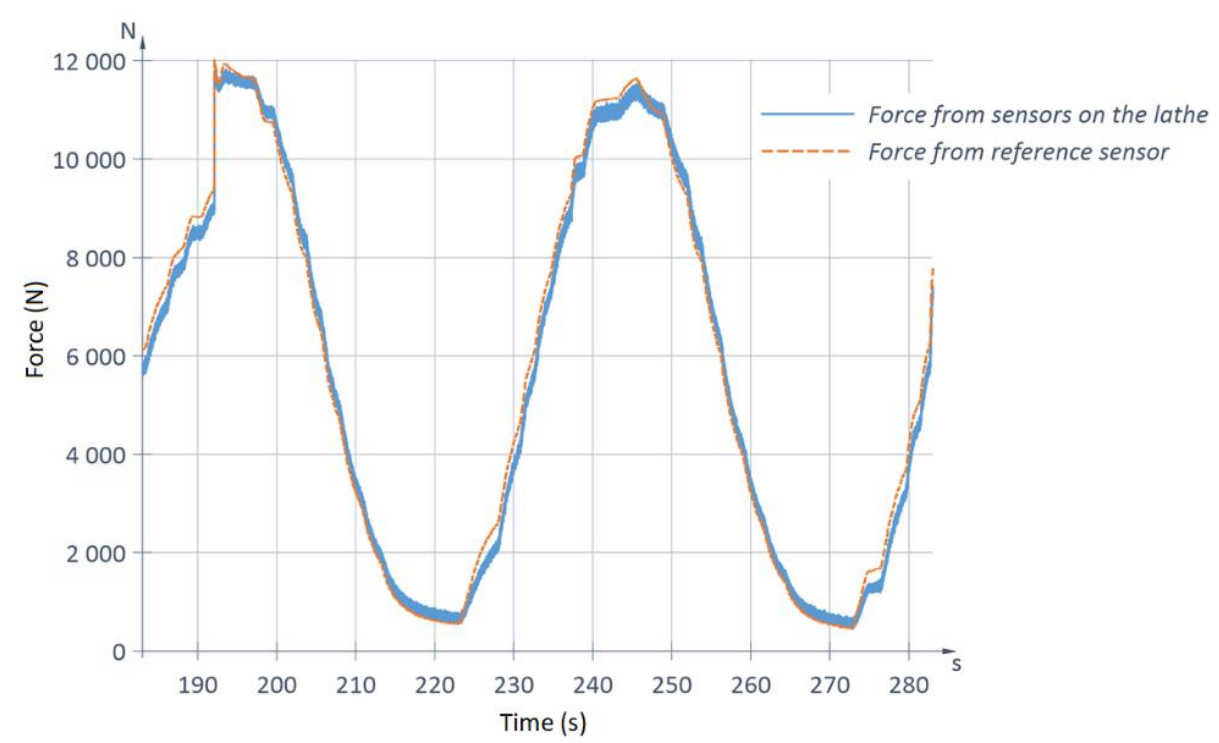

Fig. 9. Fragment of diagram of forces indicated by standard sensor and by sensors installed on lathe for force excitation with frequency of $0.02 \mathrm{~Hz}$

The measurement results were corrected for noise and plotted. The plotted graphs show that the forces acted continuously, which indicates that the system works faultlessly. The force value indicated by the graphs strongly depended on the rate of feed. This means that by changing the rate of feed one can effectively decrease or increase the load on the controlled axes. 


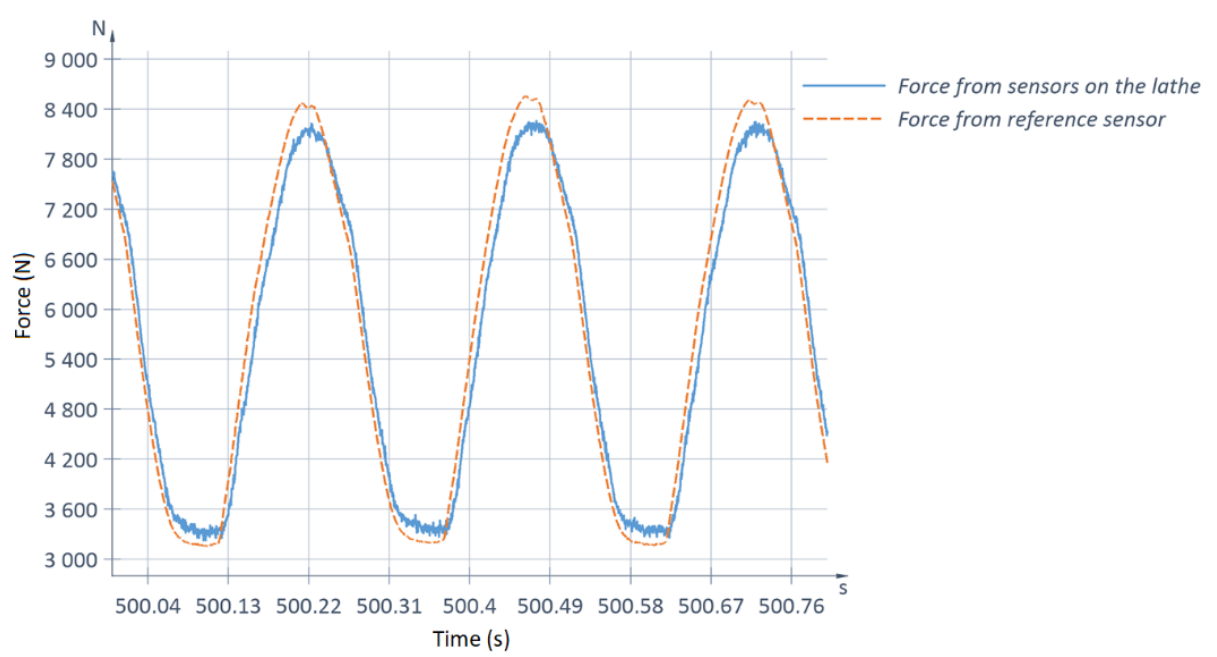

Fig. 10. Fragment of diagram of forces indicated by standard sensor and by sensors installed on lathe for force excitation with frequency of $4 \mathrm{~Hz}$

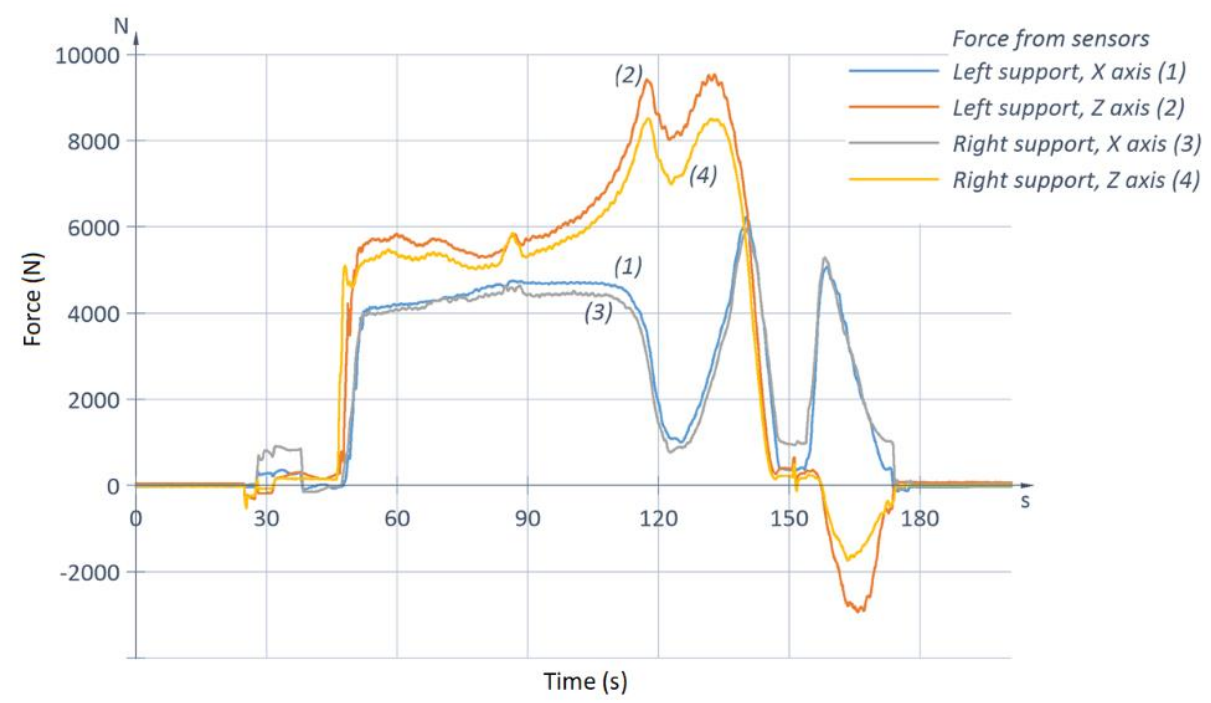

Fig. 11. Forces acting along controlled axes during machining at depth of cut of $4 \mathrm{~mm}$ and feed rate of $2 \mathrm{~mm} / \mathrm{rev}$

One can see in the above diagram (Fig. 11) that the plots of the force values generated in the course of machining on axis $Z$ and on axis $X$ have similar shapes. This is due to the fact that the machining process was conducted on a preconditioned wheelset in which the left profile and the right profile were similar. Hence one can conclude that the sensors were properly installed and calibrated, whereby the forces are correctly reflected. One can see that before and after the machining process the forces fluctuate around $0 \mathrm{kN}$, while during machining at these parameters they increase to about $9 \mathrm{kN}$. Towards the end of the process the forces along axis $Z$ assume negative values. This is caused by the machining of the internal part of the wheel's profile.

The shape of the force graphs during machining at the depth of cut of $10 \mathrm{~mm}$ and the feed rate of $1 \mathrm{~mm} / \mathrm{rev}$. is similar to that shown Fig. 11. The above tests show that the measuring system installed on the lathe yields correct results, as evidenced by the absence of distur-bances and the continuity of the measuring signals. 


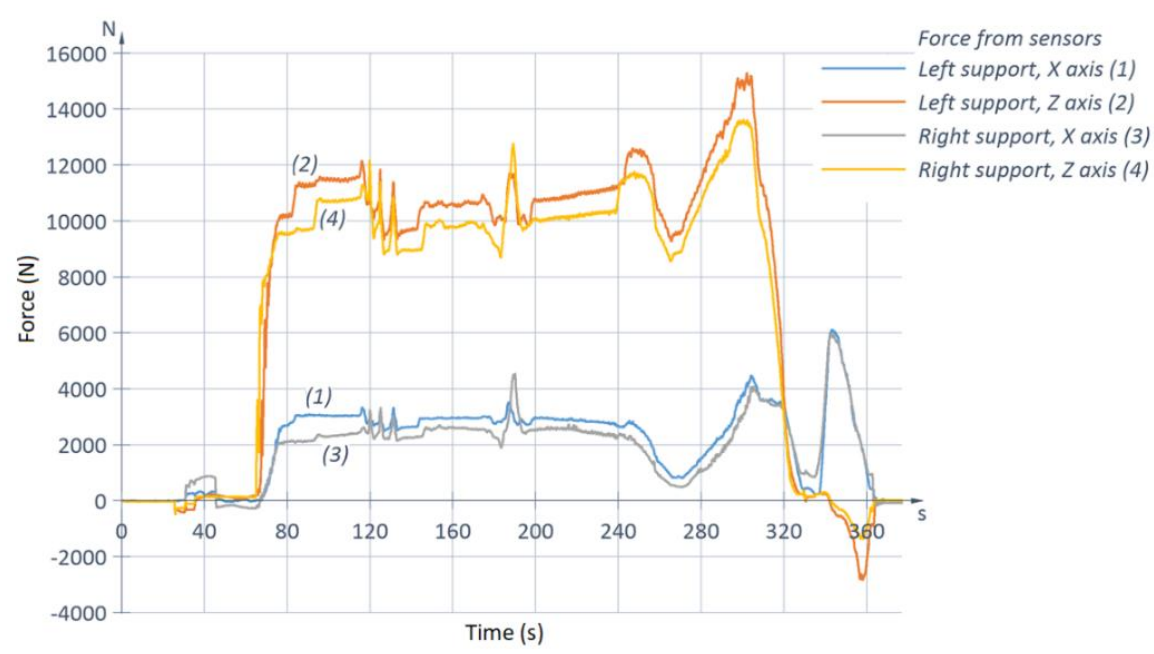

Fig. 12. Forces acting along controlled axes during machining at depth of cut of $10 \mathrm{~mm}$ and feed rate of $1 \mathrm{~mm} / \mathrm{rev}$

\section{TOOL CARRIAGE DEFLECTION ERROR MODEL}

The hydraulic actuator shown in Fig. 4b was used to test the stiffness of the lathe's tool carriages. The tests consisted in generating a force between the carriage and the wheelset by means of the hydraulic actuator and measuring the displacements with a distance sensor (Fig. 13). Carriage displacements along axis $X$ and axis $Z$ were investigated during the tests. Measurements were performed for the force acting at different angles: 0, 30, 45, 60 and $90^{\circ}$ to axis $X$ in the plane described by the axes. The force would change stepwise by a value of about $3.5 \mathrm{kN}$ in the range of $0 \mathrm{kN}-15 \mathrm{kN}$. The tests showed that the displacement caused by a given force can be described by a linear function.

Linear conversion was used to determine displacements on the basis of the force values read off the sensors installed on the lathe. Then the determined displacement values were compared with the displacements measured during the test. Assuming that the measured values constitute $100 \%$ of the error resulting from the deformation of the carriages under the action of the forces, the calculated values coincide in 62\%-94\% with the error. By creating a function appropriately responding to the measured forces one can reduce the error to the degree specified in Fig. 14.

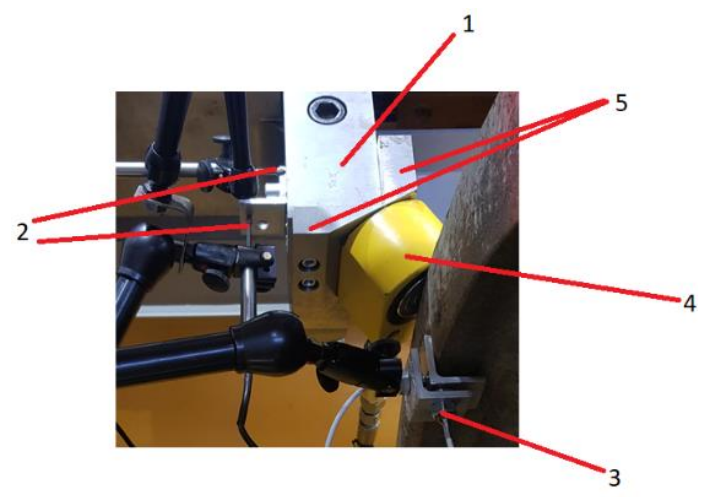

Fig. 13. Stiffness tests carried out on lathe, 1 - tool carriage, 2 - sensors measuring carriage displacements, 3 - sensors measuring wheelset displacements, 4 - hydraulic actuator, 5 - supports enabling change of exciting force action angle 


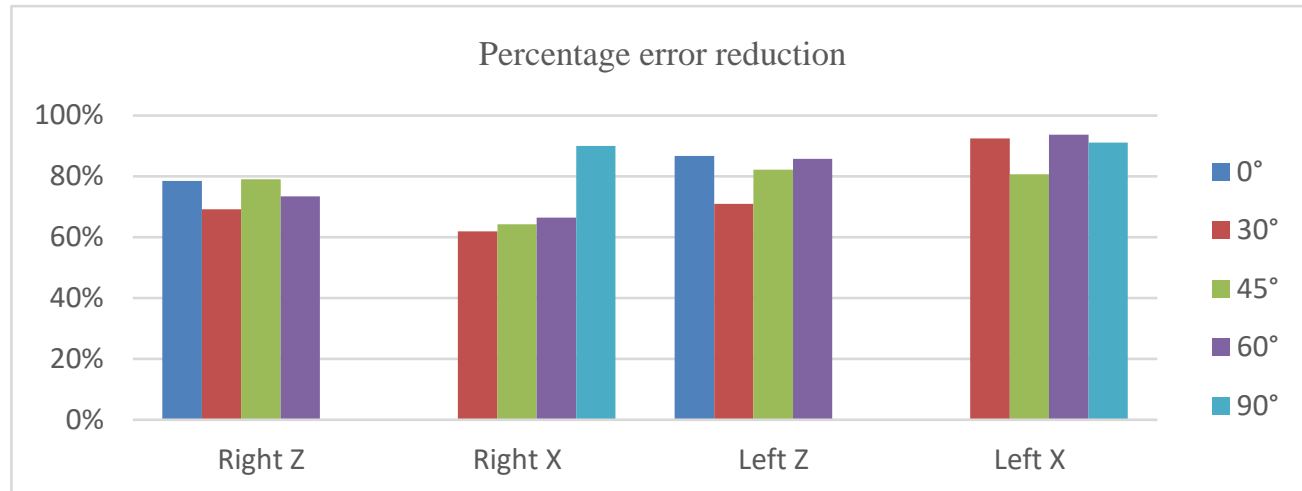

Fig. 14. Chart showing percentage reducibility of error resulting from deformation of tool carriages under action of forces

\section{CONCLUSION}

A multi-sensor system for measuring cutting force feed components has been presented. The system's design was described and the results of tests of the system structure's robustness, force transmission accuracy and responsiveness to dynamic excitations were reported.

The measuring system estimates the force acting on the cutting tool on the basis of the sum of the forces acting on a set of 3 strain gauge on axis $X$ and a set of 4 such sensors on axis $Z$, located between the selected structural members of the machine. The system was designed to work in typical rail-vehicle wheelset renovation conditions, taking into account the dimensional constraints imposed by the design solutions adopted in the target machine tool. Consequently, the system is characterized by compactness, tightness, resistance to loading with forces of up to $30 \mathrm{kN}$ and resistance to damage caused by contact with continuous and intermittent chips and it can be easily integrated with a CNC system.

The measuring system was subjected to tests to determine its force transmission and speed of response to dynamic loading effected by a hydraulic actuator. The test results were used to estimate what fraction of the values of the cutting force feed components is registered by the measuring system. Repeated tests confirmed then the system registers a constant part of the force acting on the cutting tool, whereby the actual force can be effectively estimated through the appropriate scaling of the measured values. The ultimate estimate of the actual force acting on the cutting tool in a given direction, based on the rescaled measuring system signals, is characterized by a mean relative value of up to $4.95 \%$. No drift of the measured value was observed during the tests and the slight measurement noise was eliminated through the use of an averaging filter.

When the system measuring the cutting force in the feed axes is implemented, additional information about the machining process is obtained, whereby it is possible to introduce many intelligent functions, such as: the estimation and compensation of the errors caused by the cutting force, the estimation of the cutting tool condition, the prediction or detection of tool damage, the maintenance of the constant loading of the controlled axes and so on. The above-mentioned functions can increase machining accuracy, reduce the machine's 
operating costs and increase its productivity. As part of this study one of the functions, i.e. the estimation of the error caused by the cutting force was investigated. In the artificial loading conditions this error was estimated with an accuracy of 62-94\%. Currently, the proposed method of estimating this error is tested in rail-vehicle wheelset renovation conditions and research on the compensation of so estimated errors caused by cutting forces is conducted. The planned future research will be aimed at improving the current feed control function [9] by combining the information supplied by the presented feed force measuring system with the main drive load signals available in the control system.

\section{ACKNOWLEDGEMENTS}

The authors express their thanks to NCBiR for supporting the research on intelligent machine tools, Project number POIR.04.01.04-00-0067/ 17.

\section{REFERENCES}

[1] ROY R., et al. 2016, Continuous Maintenance and the Future-Foundations and Technological Challenges, CIRP Annals, 65/2, 667-688.

[2] VERL A., FREY S., 2010, Correlation Between Feed Velocity and Preloading in Ball Screw Drives, CIRP Annals, $59 / 1,429-432$

[3] JEDRZEJEWSKI J., et al., 2019, Ball Screw Unit Precise Modelling with Dynamics of Loads and Moving Heat Sources Taken Into Account, Journal of Machine Engineering, 19/4, $27-41$.

[4] HUANG S.N., TAN K.K., et al., 2007, Tool Wear Detection and Fault Diagnosis Based on Cutting Force Monitoring, International Journal of Machine Tools and Manufacture, 47/3-4, 444-451.

[5] JEMIELNIAK K., 2002, Tool and Process Condition Monitoring, publishing house of the Warsaw University of Technology, DOI: https://doi.org/10.17814/mechanik.2017.7.64.

[6] STRYCZEK R., SZCZEPKA W., 2016, Process Factors of Impact on OEE for Lathes for Machining of Wheelset, Journal of Machine Engineering, 16/3, 126-140.

[7] ABELE E., ALTINTAS Y., BRECHER C., 2011, Machine Tools Spindle Units, CIRP Annals-Manufacturing Technology, 59/2 781-802.

[8] BRECHER Ch., HIRSCH P., WECK M., 2004, Compensation of Thermo-Elastic Machine Tool Deformation Based on Control Internal Data, CIRP Annals, 53/1, 299-304.

[9] KASPRZAK M., MĘDYK P., 2020, Approach to Measurements Feed Drive Load in Heavy Turning, Journal of Machine Engineering, 20/4, 41-58.

[10] ASTARLOA A., et al, 2021, Application of machine drive oscillations for chip breaking in heavy duty turning operations, Procedia CIRP, 101, 110-113. 